\title{
A Case Report of Juvenile Male with Inflammatory Bowel Disease with Grade I Hemorrhoids with Enteropathic Arthritis.
}

\author{
Author: Dr. Bharat Veer Manchanda ${ }^{1}$, Dr. Rochak Pandey ${ }^{2}$, Dr. Rahul \\ Chauhan $^{3}$, Dr. Shree Vasishta ${ }^{4}$, Dr. Saloni Mehra ${ }^{5}$, Dr. Shishir Pandey ${ }^{6}$ \\ ${ }^{1}$ Assi. Professor IndeptOf Medicine, Subharti Medical College, Meerut \\ ${ }^{2,3,4}$ Post Graduate In Dept Of Medicine ,Subharti Medical College, Meerut \\ ${ }^{5}$ Post Graduate In Dept Of Surgery,Subharti Medical College, Meerut \\ ${ }^{6}$ Post Graduate In Dept Of Medicine ,Subharti Medical College, Meerut
}

\begin{abstract}
Enteropathic arthritis (EA) is a spondyloarthritis (SpA) which occurs in patients with inflammatory bowel diseases (IBDs) and other gastrointestinal diseases. Diagnosis is generally established on the medical history and physical examination. It was, generally, made according to the European Spondyloarthropathy Study Group (ESSG) criteria. Rheumatic manifestations are the most frequent extraintestinal findings of IBD with a prevalence between $17 \%$ and $39 \%$.
\end{abstract}

\section{Introduction}

Enteropathic arthritis or enteroarthritis (EA) is a spondyloarthritis $(\mathrm{SpA})$ which occurs in patients with inflammatory bowel diseases (IBDs) and other gastrointestinal diseases, such as Whipple's disease (WD), celiac disease $(\mathrm{CD})$, and intestinal bypass surgery $[1,2]$.

Bargen et al. [3], in 1929, and Hench [4], in 1935, described a peripheral arthritis involvement in patients with IBD and also reported the arthritis tendency to flare with exacerbation of the colitis and to recede with the remission of bowel symptoms. Finally, in 1964, the American Rheumatism Association classified arthritis associated with IBD as independent clinical form [5], and, later, Wright and Moll included enteroarthritisdefinitively among SpA group [6].

\section{Case Report}

We report a case of a 17 year old male who presented with the chiefcomplaints of:Low back ache, Morning stiffness, Pain in the gluteal region, Joint deformities of both knees and small joints of both hands , Recurrentabdominal pain, Loose stools.The complaints had been present for the last 3 months. The patient was a non-smoker and had no history of any other chronic illnesses. The family history was non-remarkable. Therewas no history of intake of any drugs.

\section{On examination the patient had:}

Swelling of the Left 1st metacarpophalangeal joint (MCP)Flexion deformity of bilateral $2^{\text {nd }}$ and $3^{\text {rd }}$ distal interphalangeal joints (DIP)Flexion deformity of Left Proximal (PIP) and Distal Interphalangeal (DIP) JointsValgus deformity of left elbowSwelling and Valgus deformity of both knee joints. General and systemic examinations were unremarkable.Blood investigations were suggestive of microcytic hypochromic anemia with neutrophilic leukocytosis. Renal and Liver profile were normal. Blood culture did not reveal any pathogens.Urine routine was normal.RA factor and Anti-CCP were negative and CRP was strongly positive.Colonoscopic examination was reported as Hemorrhoids Grade-I.X Ray imaging of Sacroiliac joints revealed Sacroilitis of the right sacroiliac joint. Patient's immunologic profile showed positivity for HLA-B27.

\section{Discussion}

The enteropathicarthropathies are a group of rheumatologic conditions that share a link to gastrointestinal (GI) pathology. However, the term typically refers to the inflammatory spondyloarthropathies associated with inflammatory bowel disease (IBD) and to reactive arthritis caused by bacterial (eg, Shigella, Salmonella, Campylobacter, Yersinia, Clostridium difficile) and parasitic (eg, Strongyloidesstercoralis, Giardia lamblia, Ascarislumbricoides, Cryptosporidium species) infections.

Rheumatic manifestations are the most frequent extraintestinal manifestation in IBD patients with a prevalence ranging between 17\% and 39\% [7, 8] Interestingly, articular alterations can be diagnosed before, simultaneously, or after the diagnosis of IBD. The joint involvement observed in IBD is usually classified in two subsets: axial (including sacroiliitis with or without spondylitis) and peripheral. The axial involvement is found to be present in $2 \%-16 \%$ of IBD patients, with a higher prevalence in CD patients than in UC ones. Moreover, 
the prevalence of sacroiliitis (asymptomatic and symptomatic) is between $12 \%$ and $20 \%$ and association with HLA-B27 ranged from $3.9 \%$ to $18.9 \%$. Recently, some studies showed that the prevalence of axial joint involvement was higher than those reported previously, as already described by Scarpa et al. in 1992 [9]. In fact, in these studies, based on the ESSG criteria for SpA [10], the authors detected a frequency ranging between $10 \%-25 \%$ for spondylitis and $30 \%-36 \%$ for sacroiliitis $[11,12,13]$.

The peripheral involvement is a common complication in both CD and UC and its prevalence has been reported in a wide range $(0.4 \%-34.6 \%)$ of patients with IBD. It is reported to be more frequent in CD than UC (20\% and $10 \%$, resp.) and it predominantly affects the joints of the lower limbs. Women show more frequently a peripheral joint involvement, whereas men tend to have an axial involvement $[14,15]$.In our case the patient had findings suggestive of both axial and appendicular skeleton involvement in association with gastrointestinal symptoms. The diagnosis of Enteropathic arthritis was made according to European Spondyloarthropathy Study Group (ESSG) criteria and confirmed with X ray imaging of sacroiliac joints, Immunological profile and IBD on the basis of biopsy.

\section{References}

[1]. M. Leirisalo-Repo, "Enteropathic arthritis, Whipple's disease, juvenile spondyloarthropathy, and uveitis," Current Opinion in Rheumatology, vol. 6, no. 4, pp. 385-390, 1994.

[2]. A. Orlando, S. Renna, G. Perricone, and M. Cottone, "Gastrointestinal lesions associated with spondyloarthropathies," World Journal of Gastroenterology, vol. 15, no. 20, pp. 2443-2448, 2009.

[3]. J. A. Bargen, R. J. Jackman, and J. G. Kerr, "Complications and sequel of chronic ulcerative colitis," Annals of Internal Medicine, vol. 3, pp. 335-352, 1929.

[4]. P. S. Hench, "Acute and chronic arthritis," in Nelson's Loose Leaf of Surgery, G. H. Whipple, Ed., p. 104, Thomas Nelson Sons, New York, NY, USA, 1935.

[5]. B. S. Blumberg, J. J. Bunim, E. Calkins, C. L. Pirani, and N. J. Zvaifler, "Aranomenclature and classification of arthritis and rheumatism (tentative)," Arthritis and Rheumatism, vol. 7, pp. 93-97, 1964.

[6]. V. Wright and J. H. M. Moll, Seronegative Polyarthritis, North Holland Publishing Company, Amsterdam, The Netherlands, 1976.

[7]. C. Salvarani and W. Fries, "Clinical features and epidemiology of spondyloarthritides associated with inflammatory bowel disease," World Journal of Gastroenterology, vol. 15, no. 20, pp. 2449-2455, 2009.

[8]. N. Turkcapar, M. Toruner, I. Soykan et al., "The prevalence of extraintestinal manifestations and HLA association in patients with inflammatory bowel disease," Rheumatology International, vol. 26, no. 7, pp. 663-668, 2006.

[9]. R. Scarpa, A. del Puente, A. D'Arienzo et al., "The arthritis of ulcerative colitis: clinical and genetic aspects," Journal of Rheumatology, vol. 19, no. 3, pp. 373-377, 1992.

[10]. M. Dougados, S. van der Linden, R. Juhlin et al., "The European Spondylarthropathy Study Group preliminary criteria for the classification of spondylarthropathy," Arthritis and Rheumatism, vol. 34, no. 10, pp. 1218-1227, 1991.

[11]. K. deVlam, H. Mielants, C. Cuvelier, F. de Keyser, E. M. Veys, and M. de Vos, "Spondyloarthropathy is underestimated in inflammatory bowel disease: prevalence and HLA association," Journal of Rheumatology, vol. 27, no. 12, pp. 2860-2865, 2000.

[12]. P. Wordsworth, "Arthritis and inflammatory bowel disease," Current Rheumatology Reports, vol. 2, no. 2, pp. 87-88, 2000.

[13]. T. S. Rodríguez-Reyna, C. Martínez-Reyes, and J. K. Yamamoto-Furusho, "Rheumatic manifestations of inflammatory bowel disease," World Journal of Gastroenterology, vol. 15, no. 44, pp. 5517-5524, 2009.

[14]. T. R. Orchard, B. P. Wordsworth, and D. P. Jewell, "Peripheral arthropathies in inflammatory bowel disease: their articular distribution and natural history," Gut, vol. 42, no. 3, pp. 387-391, 1998

[15]. I. Yüksel, H. Ataseven, O. Başar et al., "Peripheral arthritis in the course of inflammatory bowel diseases," Digestive Diseases and Sciences, vol. 56, no. 1, pp. 183-187, 2011. 